\title{
Prevalence of Cervical Dysplasia and Associated Risk Factors among Women Presenting at a Primary Care Clinic in Nigeria
}

\author{
Olusola Aishat Mosuro, Ikeoluwa Ajayi ${ }^{1}$, Akin-Tunde Ademola Odukogbe ${ }^{2}$, Adetunji Oladeni Adeniji ${ }^{3}$, Olayiwola Oluwasola ${ }^{4}$, \\ Modupe Martha-Alice Ladipo, Achiaka Emmanuella Irabor, Effiong Essien Udo Akang ${ }^{4}$ \\ Department of Family Medicine, University College Hospital, Ibadan, ${ }^{2}$ Department of Epidemiology, Medical Statistics and Environmental Health, \\ University of Ibadan, ${ }^{2}$ Departments of Obstetrics and Gynecology, University College Hospital, Ibadan, ${ }^{3}$ LAUTECH Teaching Hospital, Ogbomoso, \\ Ibadan, ${ }^{4}$ Department of Histopathology, University College Hospital, University College Hospital, Ibadan
}

\section{A B S T R A C T}

Background: Cervical cancer is a global burden, with increasing incidence and mortality especially in developing countries where there are no clearly define national protocols or guidelines for effective screening and prompt treatment of cervical dysplasia (precancerous condition of the cervix). Most screening facilities are located in the tertiary hospitals, which are mostly not readily accessible to patients because of fear and bureaucracy of accessing services at these tertiary hospitals. In Nigeria, cervical cancer is the second most common female malignancy after breast cancer and national guidelines on effective screening is not readily available. At the general outpatients' Clinic, University College Hospital, Ibadan, screening is not well-established and patients are referred to the gynecology clinic for papanicolaou (Pap) smear, which result in poor compliance as a result of the protocol involved. Aim: To asess the prevalence and risk factors for abnormal cervical cancer screening amongst patients of the Primary Care Clinic at UCH, Ibadan, towards justifying expansion of cervical cancer screening service points in tertiary health institutions in Nigeria. Subjects and Methods: A cross-sectional study using the self-administered structured questionnaire on questions relating to the socio-demographic characteristics and lifestyle behavior including sexual history, after which Pap smear and visual inspection of the cervix with acetic acid were performed. Two hundred and eighty consented women aged 20-65 years were interviewed by one of the researchers between June and August 2012 using interviewer-administered structured questionnaires. The questionnaire sought information on their sociodemographic characteristics, and lifestyle behavior including sexual history, after which Pap smear and visual inspection of the cervix with acetic acid were done, respectively, for all the respondents at no cost. The results were analyzed using Statistical Package for Social Sciences (SPSS) version 11. Cross-tabulation was used to explore statistical associations between categorical variables. Variables were summarized using frequency distribution, means, proportions, and findings were presented in tables, histograms and pie charts. Chi-square statistic was used to assess the association between categorical variables. The level of significance was set at $P<0.05$. Result: The mean age of the women was $42.5(11.1)$ years, and their modal age was 30-39 years. The majority, 92.2\% (258/280) of the women were Yoruba. Two hundred and twenty-eight (81.4\%) of the women were married with majority $149(65.4 \%)$ in the monogamous union. Two hundred and thirteen (76.1\%) of the women had abnormal cervical cytology. One hundred and sixty-six (77.9\%) of the women with abnormal cytology had inflammatory smears, 33 (15.5\%) and $6(2.8 \%)$ had mild and moderate dysplasia, respectively, while the remaining $8(3.8 \%)$ had atypical cells. The prevalence of cervical dysplasia among all the women was $13.9 \%$ (39/280), with mild dysplasia accounting for $11.8 \%(33 / 280)$ of the total population. Atypical smears were found in $2.9 \%$ (8/280) of them. Histological findings suggestive of human papillomavirus (HPV) were found in 22 of the $33(66.7 \%)$ women who had mild dysplasia and 1 of the $6(16.7 \%)$ women who had moderate dysplasia. There was significant association between abnormal cervical cytology and age $(P=0.03)$, as well as suggested HPV infection findings $(P<0.001)$. Visual inspection of the cervix with $5 \%$ acetic acid revealed that 46 of the $280(16.4 \%)$ women had an aceto white area, while a prevalence of $47(16.8 \%)$ was found with Pap smear, though visual inspection was found not to be as sensitive in detecting dysplasia. The prevalence of cervical dysplasia among the women was $13.9 \%$, with mild dysplasia accounting for $11.8 \%$ of the total population. Atypical smears were found in $2.9 \%$ of them. There was a significant association between abnormal cervical cytology and increasing age $(P=0.03)$, as well as histological findings of HPV infection $(P<0.001)$. Conclusion: Cervical dysplasia was found to be a common health problem among women attending the primary care clinic. This underscores the need for the provision of screening service at the clinic and effective health education to promote preventive practices and inculcate screening culture among women.

\begin{tabular}{|l|l|}
\hline \multicolumn{2}{|c|}{ Access this article online } \\
\hline Quick Response Code & $\begin{array}{l}\text { Website: } \\
* * *\end{array}$ \\
\cline { 2 - 3 } & DOI: \\
& $* * *$ \\
\hline
\end{tabular}

KEY WORDS: Cervical dysplasia, Ibadan, Nigeria, risk factors, women 


\section{INTRODUCTION}

Cervical dysplasia is a disordered growth of the epithelial lining of the cervix. ${ }^{[1]}$ It is the precancerous condition of the cervix which may progress to cervical cancer over a period of time, in an average of $10-15$ years. ${ }^{[2,3]}$ Cervical dysplasia especially the low-grade lesion regresses spontaneously in a significant number of patients, allowing for expectant management with serial cytologic smears, whereas the high-grade lesions will progress to an invasive cancer if left untreated..$^{[2,3]}$

The prevalence of cervical dysplasia varies according to the socioeconomic characteristics and geographic area of the population studied, from as low as $1.05 \%$ in some family planning clinics to as high as $13.7 \%$ in women attending sexually transmitted disease (STD) clinics. ${ }^{[1]}$ Prevalence rates of $9.3 \%$ and $12 \%$ were found among the women screened in STD and family planning clinics of the University College Hospital (UCH), Ibadan respectively. ${ }^{[4,5]}$ Cervical dysplasia is mostly detected in women in their $20^{\text {th }}$ year, the peak incidence of carcinoma in situ being in women aged 25-35 years, while the incidence of cervical cancer rises after the age of 40 years. ${ }^{[1]}$

Cervical cancer is a global burden, and it is the most common cause of preventable cancer-related death especially in developing countries like Nigeria. ${ }^{\mid 2,3]}$ The incidence of cervical cancer has reduced remarkably in developed countries where there are effective, well-coordinated screening programs, and prompt treatment of cervical dysplasia. However, this incidence has been on the increase and has constituted major health problems among women in developing countries where there are no well-coordinated and effective screening programs.

There have been a lot of postulations about the predisposing factors for developing cervical cancer. It has been established to be a sexually transmitted infection, since it is commonly found in women who have had human papillomavirus (HPV) infection ${ }^{[3,6-9 \mid}$ and in those with multiple sexual partners or those whose spouses have multiple sexual partners. It has also been linked with human immunodeficiency virus, ${ }^{[10]}$ poverty, ${ }^{[11]}$ cigarette smoking, ${ }^{[8]}$ multiparity, and use of oral contraceptive pills, especially when it was used for more than 12 years. ${ }^{[12]}$

Cervical cancer screening is an important component of the World Health Organization (WHO) strategy for combating cancer. ${ }^{[2,13]}$ Available evidences indicate that cervical cancer screening programs have been effective in developed countries where a significant reduction in the incidence of and mortality from cervical cancer have been observed over the last three decades. ${ }^{[14]}$ The WHO recommends that in low-income countries every woman should be screened at least once in her lifetime between the ages of 35 and 40 years. ${ }^{[2,13]}$ The cost effectiveness of this is greater in countries with higher rates of cervical cancer and those with identifiable high-risk groups. ${ }^{\mid 2,13]}$ Even where effective screening programs exist, there is ignorance of such. ${ }^{[2,5,13,14]}$ The WHO recommendation, therefore, is for the development of national cancer strategies based on surveillance and prevention programs tailored to local needs. ${ }^{[13]}$ However, an organized screening program is difficult to implement in developing countries where resources are scarce. ${ }^{[2,3]}$ There are few if any, cytological screening programs in most developing countries, including Nigeria and coverage is insufficient to have an impact. ${ }^{[6,15,16]}$ In these countries, screening is mostly done in the context of opportunistic activities, which are often inadequately performed. ${ }^{[3,15,16]}$ It is estimated that some $40-50 \%$ of women in developed countries have been screened for cervical dysplasia by the year 1988 compared to $5 \%$ of women in developing countries..$^{[2,3,14]}$ In Nigeria, where most women are uneducated and stay in rural areas, and physicians are few, this poses a further significant limitation.

Cytological screening for the detection of precancerous diseases of the cervix has been the most successful of the public health measures introduced for the prevention of cervical cancer, though it is expensive and requires the services of a cytopathologist or cytotechnologist. ${ }^{[2,14,17]}$ Cytological screening entails the use of papanicolaou smear to identify abnormal cells on the transformation zone of the cervix.

Human papillomavirus is a member of the family of DNA tumor viruses and can also colonize mucosa or cutaneous epithelium to induce hyperproliferation. ${ }^{[18]}$ HPV cytologic changes are included in the terminology of the Bethesda classification system for cervical cytology as koilocytosis. However, the other pathognomonic changes attributed to HPV do not alone define those patients who could develop cervical cancer later. ${ }^{[18]}$ Most individuals with these HPV changes never develop either in situ or invasive carcinoma, but undergo spontaneous regression within 1-year in $63.6 \%$ of the low-grade squamous intraepithelial lesion and $38.2 \%$ of the high-grade squamous intraepithelial lesion. ${ }^{[18-20]}$

National consultations on cervical cancer control have, however, concurred that cytology-based screening programs are not feasible in most developing countries in many years to come in view of technical, financial, and manpower constraints. ${ }^{[21]}$ Screening programs for cervical cancer have thus consistently failed to meet the target population due to this lack of manpower and funds..$^{[2,22,23]}$

The current WHO recommendation is to propagate visual inspection of the cervix with 5\% acetic acid (VIA) or visual inspection with Lugol's iodine (VILI), as potential alternatives to cytology and to identify early curable cancer. ${ }^{[21,16,24]}$ A preventive strategy is more constructive, but screening 
by cytology is found to be too complex and more expensive. Considering the number of women that would need cervical cancer screening services in most tertiary hospitals and fewer cytopathologists, there is need to have VIA or VILI screening facilities available at all levels of care. ${ }^{[25,26]}$

The primary health physicians being the first contact Doctors, need to offer preventive and promotive health care to patients after attending to their immediate health needs. ${ }^{25,26]}$ These first contact physicians are in a better position to offer effective screening for cervical dysplasia at all health care levels, especially at primary and secondary care levels, for early detection, prompt treatment of moderate/severe dysplasia and appropriate referral when the need arises. ${ }^{[26]}$ This is necessary to make the screening accessible, available, and affordable to all women irrespective of their socioeconomic status and the time available to them to attend a health facility.

At the general outpatients' (GOP) Clinic, UCH, Ibadan, Nigeria screening is not well-established, and patients are referred to Gynecology clinic for papanicolaou (Pap) smear. The protocol involved in getting Pap smear done is cumbersome, and this results into poor compliance. This may underscore the need for functional cervical cancer screening service at all the GOP Clinics in order to increase coverage and uptake of this service.

\section{This study was carried out to determine}

To determine the prevalence of abnormal cervical cytology among women attending the GOP Clinic, sociodemographic and family characteristics of women with abnormal cervical cytology results and identify risk factors associated with abnormal cervical cytology among women screened.

\section{SUBJECTS AND METHODS}

This hospital-based cross-sectional descriptive study was conducted at the UCH in Ibadan, South-Western Nigeria between June $1^{\text {st }}$ and August $31^{\text {st }}$ 2012. Two hundred and eighty consented consecutive women aged 20-65 years participated in the study. Institutional ethical approval was obtained for the study. This study has attempted to determine the prevalence of abnormal cervical cytology and possible associated risk factors among women aged 20-65 years in our environment.

\section{Inclusion criteria}

All consenting women aged 20-65 years who presented at the clinic during the study period.

\section{Exclusion criteria}

Those who refused to give consent to participate, or the presence of symptoms and signs of carcinoma of the cervix or critically ill women.

\section{Data collection}

Structured questionnaires were developed by all the authors and administered to 280 consecutive women by the researchers. The questionnaire sought information on their sociodemographic characteristics and lifestyle behavior including sexual history. Physical examination, Pap smear, and visual inspection with $5 \%$ acetic acid were carried out in the consulting rooms by the researchers (OAM, IOA, AEI), who are all of consultant family physician cadre. A prestudy training and harmonization of sampling methods was conducted for researchers by AAO (consultant gynecological oncologist). Slides were processed and reported at the pathology department of the hospital by both $\mathrm{AOO}$ and EEUA. The result of the visual inspection was relayed to the women immediately while they were asked to come back in 4 weeks for the results of the Papanicolaou smear.

All patients with abnormal results beyond infection/ inflammatory findings were referred to the gynecological clinic of the hospital for specialist treatment.

\section{Sample size calculation}

The sample size was determined using prevalence of cervical dysplasia in a previous study done in Gynaecology Clinic, UCH, Ibadan. ${ }^{[5]}$ The sample size was calculated using the following formula. ${ }^{[29]}$

$N=Z^{2} P(1-P) / D^{2}$

Where,

$N=$ Minimum sample size.

$P=$ The prevalence value of $12 \%$ of dysplasia in a study done in UCH, Ibadan in $1999 . .^{[5]}$

$D=$ The absolute precision of the study which is 0.04 .

$Z=$ Area under normal curve corresponding to $95 \%$ confidence interval $=1.96$.

Therefore the sample size was calculated as 254

With correction for $10 \%$ nonresponse, it is approximated to 280 .

The results were analyzed using Statistical Package for Social Sciences (SPSS) version 11 software (SPSS Inc., Chicago, IL, USA). Cross-tabulation was used to explore statistical associations between categorical variables. Variables were summarized using frequency distribution, means, proportions, and findings were presented in tables, histograms, and pie charts. Chi-square statistic was used to 
assess the association between categorical variables. The level of significance was set at $P<0.05$.

\section{Procedure for screening (papanicolaou smear and visual inspection of the cervix with acetic acid) \\ Papanicolaou smear}

The patients were laid in lithotomy position, the cervix was exposed using the Cusco's speculum, Ayre's spatula was used to take the specimen from the ectocervix and the cytobrush to take the specimen from the endocervix. These were used to make a smear on the labeled slides; the slides were immediately fixed by spraying it with $95 \%$ ethanol before leaving it to dry. The slides were sent to the pathology laboratory of UCH for staining with Pap dye and thereafter examined by the Pathologists.

\section{Visual inspection of the cervix with acetic acid}

Visual inspection with acetic acid involves naked eye examination of the 5\% acetic acid swabbed cervix with illumination provided by a bright light source. Five percent acetic acid was daily freshly prepared before use. It was prepared from $100 \%$ acetic acid by diluting $1 \mathrm{ml}$ of $100 \%$ acetic acid with $19 \mathrm{ml}$ of distilled water. The freshly prepared 5\% acetic acid was used to swab the cervix after it was fully exposed with a Cusco's speculum. The cervix was then examined with a good light source, for aceto white area, within a minute of application of the acetic acid.

The objective of VIA is to be able to recognize clinically normal (acetic acid test negative) from abnormal cervix (acetic acid test positive) and refer abnormal cases for further evaluation, diagnosis, and appropriate treatment. ${ }^{[27,28]}$

The aim of VIA is to detect and treat cervical dysplasia in asymptomatic women, to prevent the development of cervical cancer and to complement Pap smear screening where the facility is available.

The results of the visual inspection of the cervix with acetic acid are interpreted as follows

Visual inspection of the cervix with acetic acid test negative (no aceto - white area): Follow-up in 3-5 years.

Visual inspection of the cervix with acetic acid test positive (aceto-white area(s) present): If due to infection, microscopy and culture were done and appropriate treatment instituted. Patient was re-examined after 6 weeks.

\section{RESULT}

The mean (standard deviation [SD]) age of the women was 42.5 (11.1) years; the modal age group was 30-39 years. Majority 258 of $280(92.2 \%)$ of the women were from the
Yoruba ethnic group. Two hundred and twenty-eight (228) of $280(81.4 \%)$ of the women were married with majority 149 of $280(65.4 \%)$ in monogamous union [Table 1].

Two hundred and thirteen (76.1\%) women had abnormal smears, of which 166 (59.3\%) had Inflammatory smears, 33 (11.8\%) mild dysplasia, 6 (2.1\%) moderate dysplasia, and 8 $(2.9 \%)$ atypical cells. The prevalence of cervical dysplasia among the women screened was $13.9 \%$ [Figure 1].

The mean age (SD) of women with abnormal smear was 43.6 (11.0) years; the modal age group was $40-49$ years. The majority (76.0\%) of the 258 respondents from the Yoruba ethnic group and 10 (76.9\%) of the 13 Igbo women had abnormal cervical smears. One hundred and seventy-four $(81.7 \%)$ of the women who had abnormal smear were married, with majority $111(52.1 \%)$ in a monogamous setting, while the remaining 63 (29.6\%) were in polygamous homes. Fifty-three (24.9\%) of the women with abnormal smear attained tertiary education, while 38 (17.8\%) had no formal education. The majority of women with abnormal smears, $145(68.1 \%)$ were above poverty line while the remaining 68 (31.9\%) were below poverty line [Table 2].

Age was found to be significantly associated with abnormal smear with $P=0.03$, abnormal cervical smear was more in women who were 40 years and above [Table 2]. The prevalence of dysplasia $33(38.8 \%)$ and 4 (5.0\%) were found among women who were married with most of them in polygamous union though not statistically significant [Table 3]. The prevalence of inflammatory smear increased with increasing number of children per women from 11 (57.9\%) in those who had no child to $73(83.9 \%)$ in those who had 5 or more children. Moderate dysplasia increased from $2(3.0 \%)$ in those who had 3-4 children to $4(4.6 \%)$ in those who had more than 5 children whilst, mild dysplasia and atypical smears did not follow a particular pattern

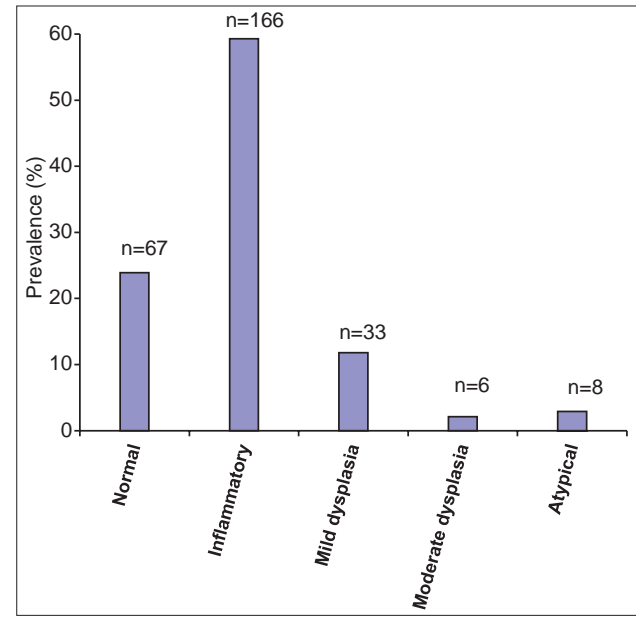

Figure 1: Categorization of cervical cytology into specific diagnostic groups 
[Table 3]. The prevalence of inflammatory smears decreased with increasing number of sexual partners except in women having 5 or more sexual partners. However, dysplasia and atypical cells were associated with increased number of sexual partners, but this was not statistically significant. Inflammatory smears were slightly more 47 (78.3\%) in those who had sexual intercourse before the age of 18 years than those who had sexual intercourse after the age of 18 years 119 (77.8\%) [Table 4]. Thirteen (21.7\%) of the women who had first sexual intercourse before the age of 18 years had dysplasia and atypical cells while $34(22.3 \%)$ of those who had first sexual intercourse after the age of 18 years had dysplasia and atypical cells. Significantly, $23(100 \%)$ of the women who had histological finding of HPV (koilocytes) had dysplasia while, 16/190 (8.4\%) of those who were negative had dysplasia. The prevalence of dysplasia and atypical cells was found to be more among women who used oral contraceptive 18/72 (25.0\%) than those who did not use

\begin{tabular}{|c|c|}
\hline \multicolumn{2}{|c|}{$\begin{array}{l}\text { Table 1: Sociodemographic characteristics of the womer } \\
\qquad(n=280)\end{array}$} \\
\hline & $n(\%)$ \\
\hline \multicolumn{2}{|l|}{ Age groups (years) } \\
\hline $20-29$ & $39(13.9)$ \\
\hline $30-39$ & $78(27.9)$ \\
\hline $40-49$ & $76(27.1)$ \\
\hline $50-59$ & $61(21.8)$ \\
\hline$\geq 60$ & $26(9.3)$ \\
\hline Mean (SD) in years & $42.5(11.1)$ \\
\hline \multicolumn{2}{|l|}{ Ethnic groups } \\
\hline Yoruba & $258(92.2)$ \\
\hline Igbo & $13(4.6)$ \\
\hline Hausa & $2(0.7)$ \\
\hline Others & $7(2.5)$ \\
\hline \multicolumn{2}{|l|}{ Marital status } \\
\hline Single & $19(6.8)$ \\
\hline Married monogamous & $149(53.2)$ \\
\hline Married polygamous & $79(28.3)$ \\
\hline Divorced/separated & $13(4.6)$ \\
\hline Widowed & $20(7.1)$ \\
\hline \multicolumn{2}{|l|}{ Educational level } \\
\hline No formal education & $43(15.3)$ \\
\hline Primary school certificate holder & $54(19.3)$ \\
\hline Secondary school uncompleted & $31(11.1)$ \\
\hline Secondary school completed & $67(23.9)$ \\
\hline Tertiary & $85(30.4)$ \\
\hline \multicolumn{2}{|l|}{ Social class } \\
\hline I & $42(15.0)$ \\
\hline ॥ & $31(11.1)$ \\
\hline III & $66(23.5)$ \\
\hline IV & $101(36.1)$ \\
\hline $\mathrm{v}$ & $40(14.3)$ \\
\hline \multicolumn{2}{|l|}{ Income } \\
\hline Above the poverty line (>4500 naira monthly) & $195(69.6)$ \\
\hline Below the poverty line ( $\leq 4500$ naira monthly) & $85(30.4)$ \\
\hline \multicolumn{2}{|l|}{ Number of children } \\
\hline 0 & $33(11.8)$ \\
\hline $1-2$ & $58(20.7)$ \\
\hline $3-4$ & $83(29.6)$ \\
\hline$\geq 5$ & $106(37.9)$ \\
\hline \multicolumn{2}{|l|}{ Stevenson's family stages } \\
\hline Emerging family & $72(25.7)$ \\
\hline Crystallizing family & $91(32.5)$ \\
\hline Interacting family & $94(33.6)$ \\
\hline Actualizing family & $23(8.2)$ \\
\hline
\end{tabular}

oral contraceptive $20.6 \%(29 / 141)$. There was a significant association between cervical dysplasia and age $(P=0.03)$, as well as histological findings suggestive of HPV infection (koilocytes) $(P<0.001)$. Koilocytes were found in $22(66.7 \%)$ of the 33 women who had mild dysplasia and $1(16.7 \%)$ of the 6 women who had moderate dysplasia [Table 4].

Table 5 displays the association between VIA and cytology. Acetowhite reaction was demonstrated in only $5(12.8 \%)$ of the 39 women who had dysplasia, 26 (15.7\%) of the 166 women who had inflammatory smears. None of the 8 women who had atypical smears had aceto white area. Aceto white reaction was seen in 15 (22.4\%) of the 67 women who had normal smears (that is false positive results). There was significant number of false negative results. This is explained as follows: $140(84.3 \%)$ of the 166 women with inflammatory

Table 2: Comparison of the sociodemographic characteristics of the women with normal and those with abnormal cytology results

\begin{tabular}{|c|c|c|c|}
\hline & $\begin{array}{c}\text { Normal } \\
(n=67)(\%)\end{array}$ & $\begin{array}{l}\text { Abnormal } \\
(n=213)(\%)\end{array}$ & $\begin{array}{c}\text { Total }(n=280) \\
(\%)\end{array}$ \\
\hline \multicolumn{4}{|l|}{ Age groups in years } \\
\hline $20-29$ & $17(25.4)$ & $22(10.3)$ & $39(13.9)$ \\
\hline $30-39$ & $20(29.8)$ & $58(27.2)$ & $78(27.9)$ \\
\hline $40-49$ & $14(20.9)$ & $62(29.1)$ & $76(27.1)$ \\
\hline $50-59$ & $14(20.9)$ & $47(22.1)$ & $61(21.8)$ \\
\hline \multirow[t]{2}{*}{$\geq 65$} & $2(3.0)$ & $24(11.3)$ & $26(9 \cdot 3)$ \\
\hline & \multicolumn{3}{|c|}{$\chi^{2}=13.472, d f=4, P=0.01 *$} \\
\hline \multicolumn{4}{|l|}{ Ethnic groups } \\
\hline Yoruba & $62(92.5)$ & $196(92.0)$ & $258(92.1)$ \\
\hline Igbo & $3(4.5)$ & $10(4.7)$ & $13(4.7)$ \\
\hline Hausa & $0(0.0)$ & $2(0.9)$ & $2(0.7)$ \\
\hline \multirow[t]{2}{*}{ Others } & $2(3.0)$ & $5(2.4)$ & $7(2.5)$ \\
\hline & \multicolumn{3}{|c|}{$\chi^{2}=0.719, \mathrm{df}=3, P=0.87$} \\
\hline \multicolumn{4}{|l|}{ Marital status } \\
\hline Single & $7(10.7)$ & $12(5.6)$ & $19(6.8)$ \\
\hline Married monogamous & $38(56.7)$ & $111(52.1)$ & $149(53.2)$ \\
\hline Married polygamous & $16(23.9)$ & $63(29.6)$ & $79(28.3)$ \\
\hline Divorced/separated & $2(3.0)$ & $11(5.2)$ & $13(4.6)$ \\
\hline \multirow[t]{2}{*}{ Widowed } & $4(6.0)$ & $16(7.5)$ & $20(7.1)$ \\
\hline & \multicolumn{3}{|c|}{$\chi^{2}=3.221, \mathrm{df}=4, P=0.52$} \\
\hline \multicolumn{4}{|l|}{ Educational status } \\
\hline No formal education & $5(7.5)$ & $38(17.8)$ & $43(15.4)$ \\
\hline Primary school completed & $13(19 \cdot 4)$ & $41(19.2)$ & $54(19.2)$ \\
\hline Secondary school uncompleted & $5(7.5)$ & $26(12.2)$ & $31(11.1)$ \\
\hline Secondary school completed & $12(17.9)$ & $55(25.8)$ & $67(23.9)$ \\
\hline \multirow[t]{2}{*}{ Tertiary } & $32(47.8)$ & $53(24 \cdot 9)$ & $85(30.4)$ \\
\hline & \multicolumn{3}{|c|}{$\chi^{2}=14.732, d f=4, P=0.01 *$} \\
\hline \multicolumn{4}{|l|}{ Social class } \\
\hline 1 & $9(13.4)$ & $33(15.5)$ & $42(15.0)$ \\
\hline II & $9(13.4)$ & $22(10.3)$ & $31(11.1)$ \\
\hline III & $15(22.4)$ & $51(23.9)$ & $66(23.6)$ \\
\hline IV & $22(32.8)$ & $79(37.1)$ & $101(36.1)$ \\
\hline \multirow[t]{2}{*}{$\mathrm{V}$} & $12(17.9)$ & $28(13.2)$ & $40(14.2)$ \\
\hline & \multicolumn{3}{|c|}{$\chi^{2}=1.706, \mathrm{df}=4, P=0.79$} \\
\hline \multicolumn{4}{|l|}{ Income } \\
\hline Below the poverty line & $17(25.4)$ & $68(31.9)$ & $85(30.4)$ \\
\hline \multirow[t]{2}{*}{ Above the poverty line } & $50(74.6)$ & $145(68.1)$ & $195(69.6)$ \\
\hline & \multicolumn{3}{|c|}{$\chi^{2}=1.035, \mathrm{df}=1, P=0.31$} \\
\hline \multicolumn{4}{|l|}{ Stevenson's family stages } \\
\hline Emerging family & $22(32.8)$ & $50(23.5)$ & $72(25.7)$ \\
\hline Crystallizing family & $24(35.8)$ & $67(31.5)$ & $91(32.5)$ \\
\hline Interacting family & $17(25.4)$ & $77(36.2)$ & $94(33.6)$ \\
\hline \multirow[t]{2}{*}{ Actualizing family } & $4(6.0)$ & $19(8.9)$ & $23(8.2)$ \\
\hline & \multicolumn{3}{|c|}{$\chi^{2}=4.339, \mathrm{df}=3, P=0.23$} \\
\hline
\end{tabular}


smears were false negative, $29(87.9 \%)$ of 33 women with mild dysplasia were false negative, whilst $5(83.3 \%)$ of 6 women with moderate dysplasia were also false negative results.

Visual inspection of the cervix with $5 \%$ acetic acid revealed that $46(16.4 \%)$ of the 280 women had an acetowhite area [Table 6]. The sensitivity and specificity of VIA using cytology as the gold standard in this study were $10.6 \%$ and $82.4 \%$, respectively [Figure 2].

\section{DISCUSSION}

Two hundred and thirteen (76.1\%) of the studied women had abnormal cervical cytology, with the majority 166 (59.3\%) having inflammatory smears. Thirty-nine (13.9\%) had dysplasia (mild and moderate), while 8 (2.9\%) had atypical cervical smears. Inflammatory changes are relatively frequent findings in cervical smears and are generally believed to be a consequence of genital infection. ${ }^{[30,31]}$ However, clinical signs of infection are frequently absent, and no consensus exists on the management of these women. ${ }^{[30]}$ The presence of inflammatory cells on cervical smears is not necessarily due to infection. ${ }^{[30]}$ It could be due to reactive or reparative cellular changes of the cervix following injury, radiation, intrauterine devices or atrophy. ${ }^{[30,32]}$ Webb et al. in 2001, however, found that there was no significant difference in the resolution of cytologic inflammatory changes after treatment with antibiotics. $^{[33]}$

Parashari et al. in Maulana Azad Medical College, New Delhi, India in 1995 found that a large proportion of women with

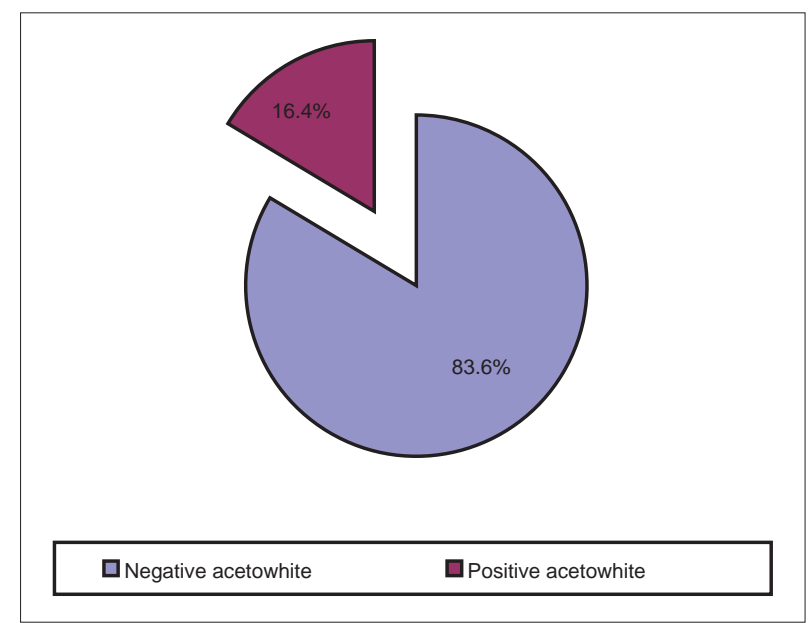

Figure 2: Prevalence of acetowhite lesion with $5 \%$ acetic acid

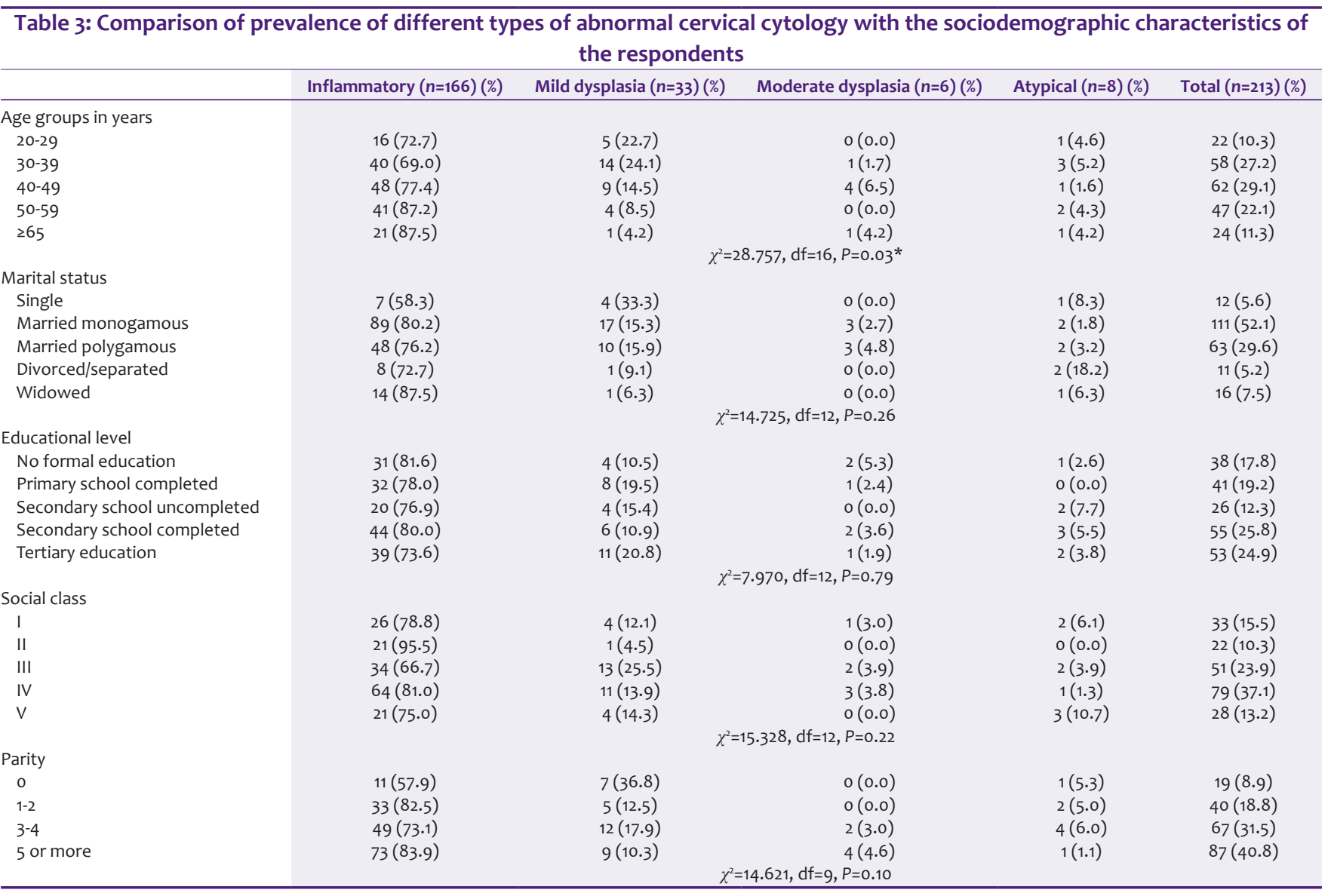

*Significant at $5 \%$ level 


\begin{tabular}{|c|c|c|c|c|c|}
\hline & Inflammatory $(n=166)(\%)$ & Mild dysplasia $(n=33)(\%)$ & Moderate dysplasia $(n=6)(\%)$ & Atypical $(n=8)(\%)$ & Total $(n=213)(\%)$ \\
\hline \multicolumn{6}{|l|}{ Number of sexual partners } \\
\hline 1 & $75(81.5)$ & $13(14.1)$ & $2(2.2)$ & $2(2.2)$ & $92(43.2)$ \\
\hline 2 & $46(75.4)$ & $11(18.0)$ & $2(3.3)$ & $2(3.3)$ & $61(28.6)$ \\
\hline 3 & $24(72.7)$ & $6(18.2)$ & $0(0.0)$ & $3(9.1)$ & $33(15.5)$ \\
\hline 4 & $14(70.0)$ & $3(15.0)$ & $2(10.0)$ & $1(5.0)$ & $20(9 \cdot 3)$ \\
\hline \multirow[t]{2}{*}{$\geq 5$} & $7(100.0)$ & $0(0.0)$ & $0(0.0)$ & $0(0.0)$ & $7(3.4)$ \\
\hline & \multicolumn{5}{|c|}{$\chi^{2}=10.989, \mathrm{df}=12, P=0.53$} \\
\hline \multicolumn{6}{|l|}{ Coitache } \\
\hline Before 18 years of age & $47(78.3)$ & $9(15.0)$ & $3(5.0)$ & $1(1.7)$ & $60(28.2)$ \\
\hline \multirow[t]{2}{*}{ After 18 years of age } & $119(77.8)$ & $24(15.7)$ & $3(2.0)$ & $7(4.6)$ & $153(71.8)$ \\
\hline & \multicolumn{5}{|c|}{$\chi^{2}=2.399, d f=3, P=0.49$} \\
\hline \multicolumn{6}{|l|}{ Koilocytes (suggestive of HPV) } \\
\hline Positive & $0(0.0)$ & $22(95.7)$ & $1(4 \cdot 3)$ & $0(0.0)$ & $23(10.8)$ \\
\hline \multirow[t]{2}{*}{ Negative } & $166(87.4)$ & $11(5.8)$ & $5(2.6)$ & $8(4.2)$ & $190(89.2)$ \\
\hline & \multicolumn{5}{|c|}{$\chi^{2}=128.214, d f=3, P<0.001^{*}$} \\
\hline \multicolumn{6}{|l|}{ Use of oral contraceptives } \\
\hline Yes & $54(75.0)$ & $11(15 \cdot 3)$ & $4(5.5)$ & $3(4.2)$ & $72(33.8)$ \\
\hline \multirow{2}{*}{ No } & $112(79.4)$ & $22(15.6)$ & $2(1.4)$ & $5(3.6)$ & $141(66.2)$ \\
\hline & \multicolumn{5}{|c|}{$\chi^{2}=3.162, d f=3, P=0.37$} \\
\hline \multicolumn{6}{|l|}{ Years of oral contraceptive use } \\
\hline Less than 12 years of use & $48(73.8)$ & $10(15.4)$ & $4(6.2)$ & $3(4.6)$ & $65(90.3)$ \\
\hline More than 12 years of use & $7(100.0)$ & $0(0.0)$ & $0(0.0)$ & $0(0.0)$ & $7(9.7)$ \\
\hline \multicolumn{6}{|c|}{ Family history of cervical cancer } \\
\hline Yes & $3(75.0)$ & $0(0.0)$ & $0(0.0)$ & $1(25.0)$ & $4(1.9)$ \\
\hline \multirow[t]{2}{*}{ No } & $163(78.0)$ & $33(15.8)$ & $6(2.9)$ & $7(3.3)$ & $209(98.1)$ \\
\hline & \multicolumn{5}{|c|}{$\chi^{2}=5.649, d f=3, P=0.13$} \\
\hline \multicolumn{6}{|l|}{ Alcohol consumption } \\
\hline Yes & $13(86.7)$ & $1(6.7)$ & $1(6.7)$ & $0(0.0)$ & $15(7.0)$ \\
\hline \multirow[t]{2}{*}{ No } & $153(77 \cdot 3)$ & $32(16.2)$ & $5(2.5)$ & $8(4.0)$ & $198(93.0)$ \\
\hline & \multicolumn{5}{|c|}{$\chi^{2}=2.424, \mathrm{df}=3, P=0.49$} \\
\hline \multicolumn{6}{|l|}{ History of STI } \\
\hline Yes & $20(87.0)$ & $2(8.7)$ & $1(4 \cdot 3)$ & $0(0.0)$ & $23(10.8)$ \\
\hline \multirow[t]{2}{*}{ No } & $146(76.8)$ & $31(16.3)$ & $5(2.6)$ & $8(4.2)$ & $190(89.2)$ \\
\hline & \multicolumn{5}{|c|}{$\chi^{2}=2.221, d f=3, P=0.53$} \\
\hline \multicolumn{6}{|l|}{ History of STI in spouse } \\
\hline Yes & $15(78.9)$ & $3(15.8)$ & $1(5 \cdot 3)$ & $0(0.0)$ & $19(8.9)$ \\
\hline No & $133(79.6)$ & $25(15.0)$ & $3(1.8)$ & $6(3.6)$ & $167(78.4)$ \\
\hline I don't know & $18(66.7)$ & $5(18.5)$ & $2(7.4)$ & $2(7.4)$ & $27(12.7)$ \\
\hline & & & $5.420, d f=6, P=0.49$ & & \\
\hline BMI & & & & & \\
\hline Chronic energy deficiency & $4(100.0)$ & $0(0.0)$ & $0(0.0)$ & $0(0.0)$ & $4(1.8)$ \\
\hline Normal & $59(73.8)$ & $16(20.0)$ & $2(2.5)$ & $3(3.7)$ & $80(37.6)$ \\
\hline Overweight & $57(75.0)$ & $11(14.5)$ & $3(3.9)$ & $5(6.6)$ & $76(35.7)$ \\
\hline Obesity & $46(86.8)$ & $6(11.3)$ & $1(1.9)$ & $0(0.0)$ & $53(24.9)$ \\
\hline & & & $3.996, d f=9, P=0.44$ & & \\
\hline
\end{tabular}

*Significant at 5\%. BMI=Body mass index, HPV=Human papillomaviruses, STI=Sexually transmitted infection

\begin{tabular}{|c|c|c|c|}
\hline able 5: Asso & $\begin{array}{l}\text { on between ur } \\
x \text { with acetic a }\end{array}$ & and cytology & the \\
\hline $\begin{array}{l}\text { Findings using Pap } \\
\text { smear }\end{array}$ & $\begin{array}{l}\text { Negative acetowhite } \\
\qquad(n=234)(\%)\end{array}$ & $\begin{array}{l}\text { Positive acetowhite } \\
\qquad(n=46)(\%)\end{array}$ & $\begin{array}{c}\text { Total }(n=280) \\
(\%)\end{array}$ \\
\hline Normal & $52(22.2)$ & $15(32.6)$ & $67(23.9)$ \\
\hline Inflammatory & $140(59.8)$ & $26(56.5)$ & $166(59.3)$ \\
\hline Mild dysplasia & $29(12.4)$ & $4(8.7)$ & $33(11.8)$ \\
\hline Moderate dysplasia & $5(2.1)$ & $1(2.2)$ & $6(2.1)$ \\
\hline Atypical & $8(3.4)$ & $0(0.0)$ & $8(2.9)$ \\
\hline & & $823, d f=4, P=0.43$ & \\
\hline
\end{tabular}

Pap=Papanicolaou

\begin{tabular}{lccc}
\hline \multicolumn{3}{c}{ Table 6: Comparing VIA with cytology } \\
\hline & \multicolumn{2}{c}{ Gold standard (Pap smear) } & Total \\
\cline { 2 - 3 } & \multicolumn{2}{c}{$\begin{array}{c}\text { Presence of cervical } \\
\text { dysplasia }\end{array}$} & $\begin{array}{c}\text { Absence of cervical } \\
\text { dysplasia }\end{array}$ \\
\hline VIA & 5 & & \\
Presence of acetowhite area & 42 & 41 & 46 \\
Absence of acetowhite area & 47 & 192 & 234 \\
Total & 233 & 280 \\
\hline VIA-Visual inspection with acetic acid, Pap=Papanicolaou & &
\end{tabular}

VIA=Visual inspection with acetic acid, Pap=Papanicolaou inflammatory smears had multiple gynecological infections and may be at risk of developing precancerous or cancerous changes. ${ }^{[34 \mid}$ They found 8 (72.7\%) of 11 women who had dysplasia detected by colposcopy and confirmed by biopsy actually had inflammatory cytology in initial Pap smears. ${ }^{[35]}$ Similar findings had also been reported by Younglove and Newman in 1978, when they discovered the prevalence of dysplasia as $36 \%$ among women with inflammatory smear after colposcopy and biopsy. ${ }^{[3]}$ It is therefore better to consider inflammatory cervical cytology smear as being abnormal smears because it could mask the dysplastic cells giving a false negative result, hence the importance of treating women with inflammatory smears and repeating the test within 3-6 months of treatment.

The prevalence of cervical dysplasia was found to be $13.9 \%$ in this study which is marginally more than prevalence of $12.0 \%$ found by Ayinde et al. in 1998 when they studied women accessing Pap smear through family planning 
clinic in the same center. ${ }^{[5]}$ This corroborated the finding of increasing prevalence of cervical dysplasia in women especially those in developing countries.

Atypical smear also known as atypical squamous cells of uncertain significance in Bethesda classification sometimes progress to mild dysplasia over a period of time. Eight (2.9\%) of the women had atypical cervical smear, these women needed to be followed up routinely.

A greater proportion of women with abnormal cervical cytology smear were in the 40-49 years age group, with dysplasia being the most common in this age group. The mean age of the 213 (76.1\%) women with abnormal cervical cytology was $43.6 \pm 11.0$ years, and the modal age group was $40-49$ years. Age is an important factor because the chances of a woman developing dysplasia increases with increasing age. The mean age for developing dysplasia and carcinoma in situ ranged from 34.7 to 38.6 years and 39.6 to 43.5 years, respectively. Babarinsa et al. in 1998 found a demonstrable increase in the incidence of cervical carcinoma, particularly among women above 30 years of age. ${ }^{[36]}$ There was a significant association between age and prevalence of abnormal cervical cytology $(P=0.01)$.

More than four-fifth $(81.7 \%)$ of the women with abnormal cervical cytology were married with greater proportion (52.1\%) in the monogamous union. The prevalence of dysplasia and atypical cells was found to be more in women in polygamous union $(23.9 \%)$ than those in monogamous (19.8\%) union which support the fact that multiple sexual partners in spouse predisposes women to developing dysplasia, ${ }^{[34]}$ this was similar to the findings of Adesina and Adeniji in the same center. ${ }^{|37|}$

The majority of the women with abnormal cervical cytology smears were living above the poverty line which was different from the known association of abnormal cervical cytology with poverty. ${ }^{[38]}$

The decrease in inflammatory cervical cytology with increasing educational status could be adduced to an improvement in the personal hygiene of woman who had formal education. The prevalence of inflammatory cervical cytology was found to increase with number of children per woman from $57.9 \%$ in those who had no child to $83.9 \%$ in those who had 5 or more children. Furthermore, there was an increase in the prevalence of inflammatory cervical cytology among women who had STDs (87.0\%) than those who had never had STDs (76.8\%). This could be because multiparous women hardly recovers from the effect of pregnancy, delivery, and lactation before conceiving again and hence tend to have nutritional deficiency of Vitamins A, C, E, beta-carotene, and folic acid. ${ }^{[39,40]}$ Studies have shown a linear trend in the association between parity and risk of developing cervical dysplasia ${ }^{[39]}$ which was not found in this study. The number of births is said to be a consistent risk factor for cervical dysplasia. ${ }^{[39-41]}$ Parity has been shown to increase the risk of cervical cancer by 2.6 in women with 3 or 4 children and by 3.8 in women with 7 or more children than women who had never given birth. ${ }^{[39-41]}$ Another reason is the fact that multiparous women tend to marry early and have multiple sexual partners or spouses have multiple sexual partners hence predisposes them to dysplasia.

A significant association was found between cervical dysplasia and HPV in this study, this had also been reported in several studies including that of Thomas et al. in 2004, in Ibadan, ${ }^{[42]}$ and Schiffman et al. in 1993, ${ }^{|43|}$ International Agency for Research on Cancer in 1995 $5^{[6]}$ and Bosch et al. in 1995. ${ }^{[7]}$

The prevalence of dysplasia and atypical cells among women who had sexual intercourse before 18 years $(21.7 \%)$ and those who had after 18 years $(22.3 \%)$ were similar. Sexual exposure before the age of 18 years is said to predispose to cervical dysplasia because women who were exposed to sexual intercourse early have a greater tendency to having multiple sexual partners which predisposes them to HPV infection. ${ }^{[18,44,45]}$

More women who had used oral contraceptive pills 18 (25.0\%) had a greater prevalence of cervical dysplasia and atypical smear than those who had never used oral contraceptive pills 29 (20.6\%). This support the documentation that long-term use (for 12 years or more) of oral contraceptive predisposes a woman to cervical dysplasia ${ }^{[46]}$ though this was found not to be statistically significant. Ursin et al. in 1994 found adenocarcinoma to be twice as common in women who used oral contraceptives than those who did not use it. ${ }^{[46]}$ Brinton in 1990 indicated that the use of oral contraceptives and the duration of their use appear to increase the risk and subsequent development of cervical dysplasia and cancer. ${ }^{[47]}$ However, study done in New Zealand showed that confounding factors such as cigarette smoking and sexual behavior were responsible for cervical dysplasia, as analysis revealed no evidence of increased risk to cervical dysplasia when these factors were taken into account..$^{[48]}$

Visual inspection of the cervix with $5 \%$ acetic acid had similar prevalence $16.4 \%$ as Pap smear $16.8 \%$. But had low sensitivity (10.6\%) and specificity (82.4\%) compared with Pap smear sensitivity (51\%) and specificity (98\%). This was similar to findings by Omigbodun et al. and Akinwuntan et al. in the same institution who stated that VIA is a highly specific method for detecting dysplasia. ${ }^{[4]}$ These findings buttress WHO suggestion that VIA could be used for mass screening in low-resource countries like Nigeria to reduce the burden of cervical cancer. ${ }^{[5,50]}$ 
Although the sensitivity and specificity of VIA were found to be low, it could still be used as an alternative to Pap smear for mass screening of women in low-resource countries like Nigeria. This will go a long way to reduce the incidence of cervical cancer in these countries since most of these women do not have access to Pap smear facilities which in most instances are provided only in tertiary hospitals.

The increase in cervical cancer awareness in this study over that found by Ajayi and Adewole in the same clinic in 1998 emphasized the importance of health education in the cervical cancer prevention program. ${ }^{[14]}$

As with any hospital-based studies, the limitations of this study were financial constraint limiting the number of subjects recruited for the study and also the prevalence of cervical dysplasia and associated risk factors identified may not fully represent those in the community.

\section{CONCLUSION}

Cervical dysplasia is a significant problem among women attending the GOP Clinic. This underscores the need for the provision of screening service at the clinic and effective health education to promote preventive practices and inculcate screening culture among women. Since VIA was found to be specific for detecting high-grade lesions, it could serve as an alternative to cytology in low-resource countries like Nigeria hence make screening for cervical dysplasia available to all women at an affordable cost. However, advocacy should be made to make Pap smear which is a superior screening test more accessible and affordable to women.

From this study, the following recommendations are made:

- Establishing a screening facility at GOP Clinic to make access easy for the women seen in this clinic

- Importance of routine cervical cancer screening should always be mentioned to every sexually active woman in health education talk given to women in the clinics. All sexually active women should, therefore, be encouraged to do routine cervical cancer screening at least once in their lifetime. The public should also be enlightened about cervical cancer and importance of routine screening to reduce the burden of cervical cancer on individual, family, and community

- All primary health care and family physicians should endeavor to learn how to screen women for cervical dysplasia. They must, therefore, offer cervical cancer screening routinely to all the women attending their clinic as an office procedure and make the result available in the shortest possible time

- Government should make protocols for routine cervical cancer screening and make facilities available even at grassroot level so that all women would have access to effective screening

- Visual inspection of the cervix with acetic acid should not be a substitute for Pap smear; as such cytotechnologists should be trained to reduce the burden on the Pathologists

- Awareness campaign about cervical dysplasia and cancer should be embarked upon in our communities to improve utilization of screening facilities available which could be achieved through our media houses.

\section{REFERENCES}

1. Holschneider $\mathrm{CH}$. Premalignant and malignant disorders of the uterine cervix. In: Current Obstetrics and Gynaecologic Diagnosis and Treatment. $9^{\text {th }}$ ed. New York, U.S.A: Lange Medical Books/Mc Graw-Hill. Medical Publishing Division; 2002. p. 894-915.

2. WHO. Cervical cancer screening in developing countries. A memorandum from a WHO meeting. Report of a WHO consultation on the control of cervical cancer in developing countries. Bull World Health Organ 2002;74:3-12.

3. Sankaranarayanan R, Budukh AM, Rajkumar R. Effective screening programmes for cervical cancer in low-and middle-income developing countries. Bull World Health Organ 2001;79:954-62.

4. Omigbodun AO, Ogunniyi JO, Adelusi B. Cervical intraepithelial neoplasia in a sexually transmitted diseases clinic population of Nigeria. J Obstet Gynaecol East Cent Africa 1988;7:74-77.

5. Ayinde AE, Adewole IF, Babarinsa IA. Trends in cervical cancer screening in Ibadan, Nigeria: A four-year review. West Afr J Med 1998; 17:25-30.

6. International Agency for Research on cancer (IARC). Human papillomavirus IAEC mongr. Eval Carcinog Risk 1995;64:267-70.

7. Bosch FX, Manos MM, Muñoz N, Sherman M, Jansen AM, Peto J, et al. Prevalence of human papillomavirus in cervical cancer: A worldwide perspective. International biological study on cervical cancer (IBSCC) Study Group. J Natl Cancer Inst 1995;87:796-802.

8. Prokopczyk B, Cox JE, Hoffmann D, Waggoner SE. Identification of tobacco-specific carcinogen in the cervical mucus of smokers and nonsmokers. J Natl Cancer Inst 1997;89:868-73.

9. ter Meulen J, Eberhardt HC, Luande J, Mgaya HN, Chang-Claude J, Mtiro $\mathrm{H}$, et al. Human papillomavirus (HPV) infection, HIV infection and cervical cancer in Tanzania, east Africa. Int J Cancer 1992;51:515-21.

10. Garzetti GG, Ciavattini A, Butini L, Vecchi A, Montroni M. Cervical dysplasia in HIV-seropositive women: Role of human papillomavirus infection and immune status. Gynecol Obstet Invest 1995;40:52-6.

11. Baquet CR, Horm JW, Gibbs T, Greenwald P. Socioeconomic factors and cancer incidence among blacks and whites. J Natl Cancer Inst 1991;83:551-7.

12. Barnhart KT, Sondheimer SJ. Contraception choice and sexually transmitted disease. Curr Opin Obstet Gynecol 1993;5:823-8.

13. Onajole AT, Ajeigbe AT. The socio-demographic characteristics and the level of awareness of the prevention of carcinoma of the cervix among commercial sex workers in Lagos, Nigeria. Niger Med Pract 2004;45:52-5.

14. Ajayi IO, Adewole IF. Determinants of utilisation of cervical cancer screening facility in a low socio-economic setting in Nigeria. J Obstet Gynaecol 1998;18:154-8.

15. Cervical cancer control in developing countries: Memorandum from a WHO meeting. Bull World Health Organ 1996;74:345-51.

16. Sankaranarayan R, Pisani P. Prevention measures in third world: Are they practical? In: Franco E, Monsorego J, editors. New Developments in Cervical Cancer Screening and Prevention. Oxford: Blackwell Science; 1997. p. 70-83. 
17. Ajayi IO, Adewole IF. Knowledge and attitude of general outpatient attendants in Nigeria to cervical cancer. Cent Afr J Med 1998;44:41-3.

18. Singleton HM, Orr JW Jr. Historical and screening for cervical dysplasia and cancer. In: Cancer of the Cervix. Philadelphia, Pennsylvania: JB Lippincott Company; 1995. p. 1-35.

19. Schiffman MH, Brinton LA. The epidemiology of cervical carcinogenesis. Cancer 1995;76:1888-901.

20. Cervical Dysplasia. Available from: http//www.womenshealthchannel. com/cervicaldysplasia/index.shtml 2001. [Last cited on 2015 March 20].

21. Sankaranarayanan R, Nene BM, Dinshaw K, Rajkumar R, Shastri S, Wesley R, et al. Early detection of cervical cancer with visual inspection methods: A summary of completed and on-going studies in India. Salud Publica Mex 2003;45 Suppl 3:S399-407.

22. Konje JC, Otolorin EO, Ogunniyi JO, Obisesan KA, Ladipo OA. The prevalence of Gardnerella vaginalis, Trichomonas vaginalis and Candida albicans in the cytology clinic at Ibadan, Nigeria. Afr J Med Med Sci 1991;20:29-34.

23. Ohaeri JU, Adeyemi OA, Omigbodun AO, Edozien LC. Knowledge of and psychosocial attitudes of cervical screening among a sample of clinic attendants. Niger Postgrad Med J 1996;3:19-24.

24. Kitchener HC, Symonds P. Detection of cervical intraepithelial neoplasia in developing countries. Lancet 1999;353:856-7.

25. Morse RM, Heffron WA. Preventive health care. In: Rakel RE, editor. Principles of Family Practice. $6^{\text {th }}$ ed. Philadelphia: W.B Sanders; 2002. p. 668-9.

26. Ajayi IO, Adewole IF. Breast and cervical cancer screening activities among family physicians in Nigeria. Afr J Med Med Sci 2002;31:305-9.

27. IARC Screening Group Anatomy and pathological basis of visual inspection with acetic acid (VIA) and with Lugol's lodine (VILI) 2005. Available from: http//www.screening.iarc.fr/viavilichap1.php?lang $=1$. [Last cited on 2015 March 20].

28. Singh V, Sehgal A, Parashari A, Sodhani P, Satyanarayana L. Early detection of cervical cancer through acetic acid application - an aided visual inspection. Singapore Med J 2001;42:351-4.

29. Araoye MO. Subject selection. In: Research Methodology with Statistics for Health and Social Sciences. $1^{\text {st }}$ ed. Ilorin, Nigeria: Nathadex Publisher; 2003. p. 115-29.

30. Ayres de Campos D, Nogueira A, Magalhães F, Bayer P, Monteiro J, Lameirão A, et al. Inflammatory smears in cervicovaginal cytology. A finding meaning infection? Acta Med Port 1997;10:637-41.

31. Edwards SK, Sonnex C. Influence of genital infection on cervical cytology. Sex Transm Infect 1998;74:271-3.

32. Herbst AL. The Bethesda System for cervical/vaginal cytologic diagnoses: A note of caution. Obstet Gynecol 1990;76:449-50.

33. Webb JC, Wharton GG, Hawley-Bowland C, Carlson JW. Efficacy of treatment of inflammatory cytologic abnormalities detected by papanicolaou smears: A pilot study. J Low Genit Tract Dis 2001;5:82-4.

34. Singh V, Sehgal A, Chattopadhya D, Parashari A, Gupta MM, Satyanarayana L. Association between reproductive tract infections and cervical inflammatory epithelial changes. Sex Transm Dis 1995;22:25-30.
35. Parashari A, Singh V, Gupta MM, Satyanarayana L, Chattopadhya D, Sodhani P, et al. Significance of inflammatory cervical smears. APMIS 1995; 103:273-8.

36. Babarinsa IA, Akang EE, Adewole IF. Pattern of gynaecological malignancies at the Ibadan cancer registry 1976-1995. Nig Q J Hosp Med 1998;8:103-6.

37. Louie KS, de Sanjose S, Diaz M, Castellsagué X, Herrero R, Meijer $\mathrm{CJ}$ et al. Early age at first sexual intercourse and early pregnancy are risk factors for cervical cancer in developing countries. Br J Cancer 2009; 100:1191-7.

38. dos Santos Silva I, Beral V. Socioeconomic differences in reproductive behaviour. IARC Sci Publ 1997;138:285-308.

39. Muñoz N, Franceschi S, Bosetti C, Moreno V, Herrero R, Smith JS, et al. Role of parity and human papillomavirus in cervical cancer: The IARC multicentric case-control study. Lancet 2002;359:1093-101.

40. Radha A, Pai Y, Nalini P. High fertility: Risk factor for carcinoma of the cervix. J Fam Welf 1995;41:48-51.

41. Brinton LA, Reeves WC, Brenes MM, Herrero R, de Britton RC, Gaitan E, et al. Parity as a risk factor for cervical cancer. Am J Epidemiol 1989;130:486-96.

42. Thomas JO, Herrero R, Omigbodun AA, Ojemakinde K, Ajayi IO, Fawole A, et al. Prevalence of papillomavirus infection in women in Ibadan, Nigeria: A population-based study. BrJ Cancer 2004;90:638-45.

43. Schiffman MH, Bauer HM, Hoover RN, Glass AG, Cadell DM, Rush BB, et al. Epidemiologic evidence showing that human papillomavirus infection causes most cervical intraepithelial neoplasia. J Natl Cancer Inst 1993;85:958-64.

44. McIntosh N. HPV and Cervical Cancer. Cancer 2000;89:826-33.

45. Cervical Cancer Prevention Fact Sheet. Risk Factors for Cervical Cancer: Evidence to Date. Available from: http://www.screening.iarc. fr/doc/RH-fs-risk-factors.pdf. [Last cited on 2015 March 20]

46. Ursin G, Peters RK, Henderson BE, d'Ablaing G $3^{\text {rd }}$, Monroe KR, Pike MC. Oral contraceptive use and adenocarcinoma of cervix. Lancet 1994;344:1390-4.

47. Brinton LA, Reeves WC, Brenes MM, Herrero R, de Britton RC, Gaitan E, et al. Oral contraceptive use and risk of invasive cervical cancer. Int J Epidemiol 1990;19:4-11.

48. Risk of cervical dysplasia in users of oral contraceptives, intrauterine devices or depot-medroxy-progesterone acetate. The New Zealand contraception and health study group. Contraception 1994;50:431-41.

49. Adewole IF, Benedet JL, Brian CT, Follen M. Evolving a strategic approach to cervical cancer control in Africa. Gynaecol Oncol 2005;99:8209-12.

50. Akinwuntan AL, Adesina OA, Okolo CA, Oluwasola OA, Oladokun A, Ifemeje AA, et al. Correlation of cervical cytology and visual inspection with acetic acid in HIV-positive women. J Obstet Gynaecol 2008;28:638-41.

How to cite this article:*** 